Germany. PLoS One. 8(1):e53415.

4. Pergolizzi S, Santacaterina A, Adamo B, et al(2011). Induction chemotherapy with paclitaxel and cisplatin to concurrent radiotherapy and weekly paclitaxel in the treatment of locoregionally advanced, stage IV (M0), head and neck squamous cell carcinoma. Mature results of a prospective study. Radiation Oncology.6(1):162.

5. Ngô Xuân Quý (2020). Nghiên cứu kết quả hóa trị bố trơ trước phác đồ TC và tỷ lệ bộc lô môt số dấu ấn liên quan đến ung thư lưỡi giai đoạn IIII-IV(M0).

6. Zhong LC, Lu F, Ma F, et al(2015). Ultrasoundguided fine-needle aspiration of thyroid nodules: does the size limit its efficiency? Int J Clin Exp Pathol.8(3):3155-3159.

7. Vokes EE, Stenson K, Rosen FR, et al(2003). Weekly carboplatin and paclitaxel followed by concomitant paclitaxel, fluorouracil, and hydroxyurea chemoradiotherapy: curative and organ-preserving therapy for advanced head and neck cancer. J Clin Oncol.

8. Zhong $L$ ping, Zhang $C$ ping, Ren $G$ xin, et al(2013). Randomized Phase III Trial of Induction Chemotherapy With Docetaxel, Cisplatin, and Fluorouracil Followed by Surgery Versus Up-Front Surgery in Locally Advanced Resectable Oral Squamous Cell Carcinoma.

9. Schwam ZG, Sosa JA, Roman S, Judson BL(2015). Complications and mortality following surgery for oral cavity cancer: analysis of 408 cases. Laryngoscope. 125(8):1869-

10. Lê Văn Quảng (2013). Nghiên cứu điều trị ung thư lưỡi giai đoan III,IV(M0) bằng cisplatin-5FU bổ trợ trước phấu thuật và/hoặc xa trị. Luận án Tiến sĩ Y hoc. Trường Đại hoc Y Hà Nội

\title{
GIÁ TRI CHẨN ĐOÁN CỦA HS-TROPONIN T THỜI ĐIỂM 0- 1H Ở BÊNNH NHÂN ĐAU NGỰC ĐẾN CẤP CỨU
}

\section{TÓM TẮT}

Nghiên cứu nhằm tìm hiểu giá trị của xét nghiệm hs Troponin $\mathrm{T}$ thời điểm $0-1 \mathrm{~h}$ trong chẩn đoán hối chứng vành cấp ở các bênh nhân đau ngực vào cấp cứu. Đây là một nghiên cứu mô tả cắt ngang trên 290 bệnh nhân đau ngực vào cấp cứu. Các bệnh nhân được làm 2 mẫu xét nghiệm hs troponin T lúc nhập viên và sau $1 \mathrm{~h}$ để tìm hiểu giá tri của xét nghiêm với bệnh nhân đau ngực cấp. Kết quả cho thấy tỷ lệ bệnh nhân đau ngực vào cấp cứu do HCVC găp ở $49,7 \%$ trường hợp. Giá trị và biến thiên nồng độ troponin thời điểm $0-1$ h có hiêu quả rất tốt trong chẩn đoán NMCT cấp với diện tích dưới đường cong (AUC) lần lượt là: 0,$863 ; 0,914 ; 0,932$ (với $\mathrm{p}<0.001$ ). Với ngưỡng giá tri hs troponin T lúc nhập viện là $5 \mathrm{ng} / \mathrm{l}$ để loại trừ chẩn đoán NMCT (Rule-out) thì độ nhay là 0,989 và giá trị dự báo âm tính là 94,9\%. Trong khi đó nểu lấy ngưỡng $52 \mathrm{ng} / \mathrm{l}$ để chẩn đoán NMCT (Rule-in) thì độ đặc hiệu là 0,957 giá trị dự báo dương tính là 85,6\%. Với ngưỡng biến thiên Hs-Troponin T $0-1 \mathrm{~h}$ là $5 \mathrm{ng} / \mathrm{l}$, thì độ đặc hiệu chẩn đoán NMCT là 0,957 giá trị dự báo dương tính là $88,7 \%$. Nghiên cứu cho thây xét nghiêm hs-Troponin $\mathrm{T}$ và biến thiên hs-Troponin $\mathrm{T}$ 01 h có giá trị cao trong chẩn đoán NMCT ở bệnh nhân đau ngực vào cấp cứu.

Từ khóa: Đau ngực cấp, hội chứng vành cấp, nhồi máu cơ tim cấp, Hs-Troponin T.

\section{${ }^{1}$ Bệnh viện đa khoa tỉnh Hà Nam \\ ${ }^{2}$ Trường Đại học Y Hà Nội \\ Chịu trách nhiệm chính: Nguyễn Trọng Khoa \\ Email: Drtrongkhoa@gmail.com}

Ngày nhânn bài: 7.9.2021

Ngày phản biện khoa học: 29.10.2021

Ngày duyệt bài: 8.11.2021

\section{Nguyễn Trọng Khoa ${ }^{1}$, Hoàng Bùi Hải ${ }^{2}$}

\section{SUMMARY}

DIAGNOSTIC VALUE OF HS-TROPONIN T AT 01 IH IN PATIENTS WITH CHEST PAIN COMING

TO THE EMERGENCY DEPARTMENT

The study aimed to find out the value of the hs Troponin $\mathrm{T}$ test at $0-1 \mathrm{~h}$ in the diagnosis of acute coronary syndrome in patients with chest pain entering the emergency department. This is a crosssectional descriptive study of 290 patients with chest pain presenting to the emergency department. The patients were made 2 samples of hs troponin $T$ at admission and after 1 hour to find out the value of the test for patients with chest pain. The results showed that the rate of patients with chest pain coming to the emergency department due to ACS was found in $49.7 \%$ of cases. The value and variation of troponin concentration at $0-1 \mathrm{~h}$ are very effective in diagnosing acute MI with the area under the curve (AUC) respectively: $0.863 ; 0.914 ; 0.932$ (with $p<0.001$ ). With a threshold value of hs troponin $\mathrm{T}$ at admission of $5 \mathrm{ng} / \mathrm{l}$ to exclude the diagnosis of MI (Rule-out), the sensitivity was 0.989 and the negative predictive value was $94.9 \%$. Meanwhile, if the threshold of $52 \mathrm{ng} / \mathrm{l}$ is taken to diagnose MI (Rule-in), the specificity is 0.957 , the positive predictive value is $85.6 \%$. With the threshold of variation for Hs-Troponin T 0-1h of $5 \mathrm{ng} / \mathrm{l}$, the specificity of MI diagnosis was 0.957 , the positive predictive value was $88.7 \%$. The study showed that the Hs-Troponin $\mathrm{T}$ test and the Hs-Troponin $\mathrm{T} 0-1 \mathrm{~h}$ variation had high values in diagnosing $\mathrm{MI}$ in patients with chest pain entering the emergency department.

Keywords: Acute chest pain, acute coronary syndrome, acute myocardial infarction, Hs-Troponin $\mathrm{T}$.

\section{I. ĐĂT VẤN ĐỀ}

Đau ngực là cấp cứu thường gặp tại khoa cấp 
cứu. Đây là lý do phổ biến thứ 2 khiến bệnh nhân phải đi khám bệnh ${ }^{1}$. Trong số các nguyên nhân gây đau ngực cấp, NMCT là một trong những lý do chính gây tử vong hàng đâu tại các nước phát triển và ngày càng gia tăng tại các nước đang phát triển trong đó có Việt Nam.

Xét nghiệm các mẫu troponin tại các thời điểm khác nhau là cần thiết để chẩn đoán NMCT cấp và phân biệt tình trạng tổn thương cơ tim cấp và mạn tính². Căn cứ vào giá trị troponin khi vào viện và biến đổi sau $1 \mathrm{~h}$ giúp chẩn đoán và loại trừ sớm NMCT cấp ở bệnh nhân đau ngực ở khoa cấp cứu ${ }^{3}$. Sự tăng và biến đổi troponin trên ngưỡng bách phần vị 99 rất đặc hiệu cho tổn thương cơ tim trong NMCT, tuy nhiển cũng có thể gặp trong các trường hợp đau ngực cấp khác như tắc động mạch phổi cấp, lóc tách động mạch chử ${ }^{4} .$. Vì vậy chúng tôi thực hiện nghiên cứu với mục tiêu: tìm hiêu giá trị chẩn đoán hs Troponin T với các bệnh nhân đau ngực vào cấp cứu.

\section{II. ĐỐI TƯợNG VÀ PHƯƠNG PHÁP NGHIÊN CỨU}

1. Đối tượng nghiên cứu. Nghiên cứu gồm những bệnh nhân vào viện vì triệu chứng đau ngực cấp nhập viện khoa cấp cứu- Hồi sức tích cực bệnh viện đại học Y Hà Nội.

Tiểu chuẩn lựa chọn. Bệnh nhân đủ 18 tuổi, đồng ý tham gia nghiên cứu; Có đủ 2 mẫu xét nghiệm hs Troponin $T$ thời điểm lúc nhập viện và sau $1 \mathrm{~h}$ vào viện

Tiêu chuẩn loại trừ. Bệnh nhân không đủ dữ liệu nghiên cứu; Thời gian xét nghiệm giữa 2 mẫu không phù hợp (thời gian giữa 2 xét nghiệm có thể dao động trong khoảng 50-80 phút); Bệnh nhân và gia đình không đồng ý nghiên cứu

\section{Phương pháp nghiên cứu}

Thiết kế nghiên cứu: Nghiên cứu mô tả cắt ngang có theo dõi.
Công thức tính cỡ mẫu: Sử dụng cõ̃ mẫu thuận tiện

Xét nghiệm hs troponin T: Thực hiện trên máy cobas E601 khoảng đo: 3-10000 ng/L, giới hạn trống $3 \mathrm{ng} / \mathrm{l}$, giới hạn phát hiện $5 \mathrm{ng} / \mathrm{l}$, giới hạn định lượng $13 \mathrm{ng} / \mathrm{l}$. Giá trị tham khảo bách phân vị 99 người bình thường khỏe mạnh 14ng/l.

Quy trình nghiên cứu. Các bệnh nhân đau ngực cấp vào cấp cứu được khám, làm điện tim, xét nghiệm Troponin $T$ lúc nhập viện và sau $1 \mathrm{~h}$. Chẩn đoán cuối cùng của bệnh nhân được ghi nhận khi bệnh nhân ra viện, những chẩn đoán có liên quan đến bệnh lý tim mạch sẽ được quyết định dựa trên sự thống nhất của bác sĩ cấp cứu và 1 bác sĩ tim mạch. Các bệnh nhân sau khi ra viện sẽ được theo dõi sau 1 tháng thông qua gọi điện thoại trực tiếp, các bệnh nhân phải tái khám hoặc tái nhập viện cũng sẽ̃ được theo dõi trên hệ thổng theo dõi bệnh nhân nội trú và ngoại trú của bệnh viện.

\section{Địa điểm, thời gian nghiên cứu}

Địa điểm: Khoa Cấp cứu - Hồi sức tích cực Bệnh viện Đại học Y Hà Nội

Thời gian: Từ 01/08/2020 Tới 01/09/2021

3. Đạo đức nghiên cứu. Thực hiện lấy và phân tích 2 mẫu troponin T đã được thông qua và khuyến cáo áp dụng trong phác đồ Hs troponin T 0-1h bởi Bộ y tế trong quyết định ban hành tài liệu chuyên môn "Hướng dẫn chẩn đoán và xử lý hội chứng vành cấp -2019". Nghiên cứu chỉ nhằm mục đích khoa học, không ảnh hưởng đến sức khỏe, không làm thay đổi phác đồ điêu trị cho người bệnh.

\section{KẾT QUẢ NGHIÊN CỨU}

Trong thời gian nghiên cứu, chúng tôi ghi nhận 413 bệnh nhân trong đó có 290 bệnh nhân thỏa mãn tiểu chuẩn lựa chọn và loại trừ.

1. Đặc điểm chung của đối tượng nghiên cứu

Bảng 1. Đặc điểm chung của đổi tượng nghiên cứu

\begin{tabular}{|c|c|c|c|c|c|}
\hline \multicolumn{2}{|c|}{ Đặc điểm } & $\begin{array}{c}\text { Tổng } \\
(\mathrm{N}=290)\end{array}$ & $\begin{array}{c}\text { Bệnh nhân } \\
\text { HCVC } \\
(\mathrm{N}=144)\end{array}$ & $\begin{array}{c}\text { Không } \\
\text { HCVC } \\
(\mathrm{N}=146)\end{array}$ & Giá trị p \\
\hline \multicolumn{2}{|c|}{ Tuối- TB (Tứ phân vị) } & $63(55-73)$ & $65(58-74)$ & $62(53-72)$ & 0,42 \\
\hline Giới & Nam & $183(63)$ & $105(73)$ & $78(53)$ & \multirow{2}{*}{0,01} \\
\hline & Nũ̃ & $107(47)$ & $39(27)$ & $68(37)$ & \\
\hline \multicolumn{6}{|c|}{ Yều tố nguy cơ } \\
\hline Tăng & & $139(48)$ & $93(65)$ & $46(32)$ & $<0,001$ \\
\hline Đái th & $\%$ & $59(20)$ & $46(32)$ & $13(9)$ & $<0,001$ \\
\hline Rối loa & (\%) & $19(7)$ & $9(10)$ & $5(7)$ & 0,03 \\
\hline Hút & & $56(19)$ & $49(34)$ & $7(5)$ & $<0,001$ \\
\hline \multicolumn{6}{|c|}{ Tiền sử } \\
\hline \multirow{2}{*}{\multicolumn{2}{|c|}{$\begin{array}{c}\text { Suy tim } \\
\text { Stent mach vành }\end{array}$}} & $24(8)$ & $18(12)$ & $6(4)$ & 0,01 \\
\hline & & $30(10)$ & $22(15)$ & $8(6)$ & 0,006 \\
\hline
\end{tabular}




\begin{tabular}{|c|c|c|c|c|}
\hline Bệnh đm ngoại vi & $3(1)$ & $3(2)$ & $0(0)$ & 0,121 \\
\hline Tai biến mạch não & $11(4)$ & $9(6)$ & $2(1)$ & 0,03 \\
\hline
\end{tabular}

Nhận xét: Tuối trung bình của đối tượng nghiên cứu là 63 tuối trong đó tuối trung bình của bệnh nhân HCVC là 65 tuổi và những bệnh nhân khác là 62 tuổi, khác biệt giữa 2 nhóm là không có ý nghĩa thống kê với $p=0,42$. Tuy nhiên yếu tố nguy cơ và tiền sử các bệnh lý tim mạch của 2 nhóm là khác biệt có ý nghĩa thống kê với $p<0,05$.

2. Biến đổi nồng độ $H s$ troponin $T$ thời điểm 0-1h ở bệnh nhân đau ngực cấp.

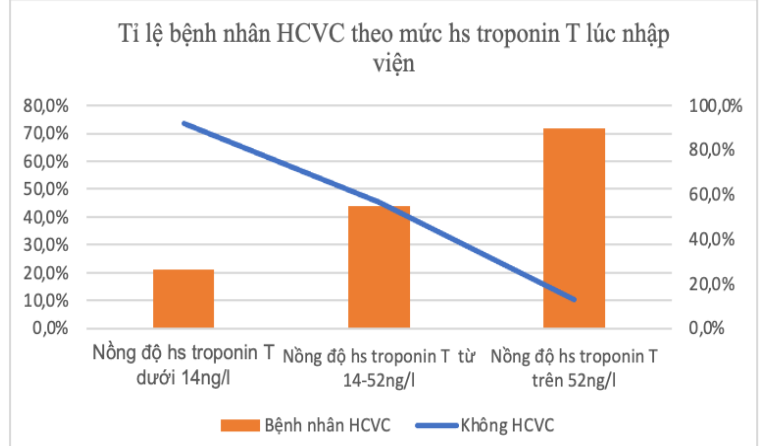

Biểu đồ 1. Tỉ lệ HCVC theo nồng độ hs troponin $T$

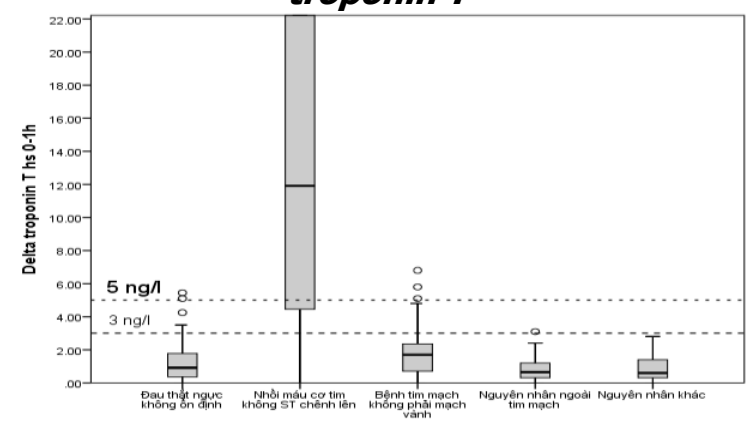

Biểu đồ 2: Biến đổi hs troponin T thời điểm 0-1h ở bênh nhân đau ngực

Nhận xét: Có $26,6 \%$ bệnh nhân HCVC có mức troponin T lúc nhập viện dưới $14 \mathrm{ng} / \mathrm{l}$.
Những bệnh nhân có mức troponin T trên $52 \mathrm{ng} / \mathrm{l}$ thì tỉ lệ NMCT ở những bệnh nhân này là $89,9 \%$

Với điểm cắt $5 \mathrm{ng} / \mathrm{l}$, tăng hoặc giảm nồng độ hs troponin $T$ thời điểm nhập viện và sau $1 \mathrm{~h}>5$ $n g / l$ chủ yếu gặp ở bệnh nhân NMCT $(n=63$ chiếm $85,1 \%$ ). Các giá trị trên $5 \mathrm{ng} / \mathrm{l}$ ở các nhóm bệnh nhân khác chủ yếu nằm ở các giá trị ngoại vi (outliers). Những bệnh nhân này chủ yếu là những bệnh nhân có tình trạng tổn thương cơ tim trực tiếp như viêm cơ tim, tắc mạch phổi có sốc...

3. Giá trị chẩn đoán của Hs troponin $T$ 0-1h và Delta troponin T 0-1h ở bệnh nhân NMCT cấp không ST chênh lên.

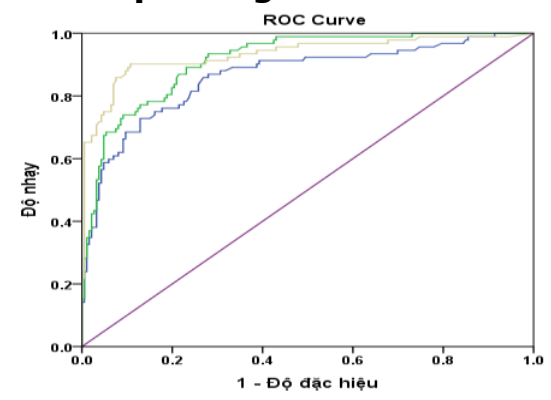

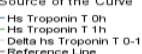

Hình 1. Đường cong ROC chẩn đoán NMCT không ST

Sử dụng đường cong ROC tính độ nhạy độ đặc hiệu của giá trị hs troponin $\mathrm{T}$ trong chẩn đoán nhồi máu cơ tim cấp không ST chênh chúng tôi có kết quả như sau.

Bảng 2. Giá trị chẩn đoán của hs troponin T ở bệnh nhân NMCT câp không ST chênh

\begin{tabular}{|c|c|c|c|c|}
\hline Biến đánh giá & $\begin{array}{c}\text { AUC } \\
(95 \% \mathrm{CI}) \\
(\mathrm{p}<0.001)\end{array}$ & $\begin{array}{c}\text { Điếm cắt } 1 \\
\text { (Se- Sp) } \\
\text { (PPV-NPV) }\end{array}$ & $\begin{array}{c}\text { Điếm cắt } 2 \\
\text { (Se-Sp) } \\
\text { (PPV-NPV) }\end{array}$ & $\begin{array}{c}\text { Điếm cắt } 3 \\
\text { (Se-Sp) } \\
\text { (PPV-NPV) }\end{array}$ \\
\hline $\begin{array}{c}\text { Hs troponin T Oh } \\
(\mathrm{ng} / \mathrm{I})\end{array}$ & $\begin{array}{c}0,863 \\
(0,814-0,912)\end{array}$ & $\begin{array}{c}5(0,989-0,097) \\
\text { NPV: } 0,949\end{array}$ & $\begin{array}{c}14(0,891-0,677) \\
(0,557-0,928)\end{array}$ & $\begin{array}{c}52(0,543-0,957) \\
(0,856-0,816)\end{array}$ \\
\hline $\begin{array}{c}\text { Hs troponin T 1h } \\
(\mathrm{ng} / \mathrm{I})\end{array}$ & $\begin{array}{c}0,914 \\
(0,880-0,947)\end{array}$ & $\begin{array}{c}14(0,935-0,677) \\
(0,576-0,956) \\
\end{array}$ & $\begin{array}{c}52(0,630-0,952) \\
(0,860-0,845)\end{array}$ & $\begin{array}{c}100(0,480-0,968) \\
P P V=0,877\end{array}$ \\
\hline $\begin{array}{c}\text { Delta Hs troponin } \\
\mathrm{T}(\mathrm{ng} / \mathrm{I})\end{array}$ & $\begin{array}{c}0,932 \\
(0,896-0,968)\end{array}$ & $\begin{array}{c}3(0,859-0,914) \\
(0,824-0,932)\end{array}$ & $\begin{array}{c}5(0,717-0,957) \\
(0,887-0,877)\end{array}$ & $\begin{array}{c}7(0,641-0,995) \\
P P V=0,983\end{array}$ \\
\hline
\end{tabular}

Nhận xét: Diện tích dưới đường cong (AUC) của Hs troponin T Oh, 1h, Delta hs troponin T 01 hần lượt là: 0,$863 ; 0,914 ; 0,932$. AUC khác biệt 0,5 có ý nghĩa thống kê với $p<0,001$.
Xét nghiệm Hs troponin T Oh: Sử dụng giá trị $5 \mathrm{ng} / \mathrm{l}$ của xét nghiệm Hs troponin T lúc nhập viện để loại trừ nhồi máu cơ tim thì độ nhạy là 0,989 , giá trị dự báo âm tính là 0,949. 
Với điểm cắt 14ng/l của xét nghiệm Hs troponin T lúc nhập viện độ nhạy chẩn đoán NMCT là 0,891 độ đặc hiệu 0,677 . Với điểm cắt $52 \mathrm{ng} / \mathrm{l}$ độ đặc hiệu là 0,957 giá trị dự báo dương tính là 0,856 .

Delta hs troponin T 0-1h. Sử dụng điểm cắt 3ng/l để loại trừ NMCT thì độ nhạy là 0,859 , giá trị dự báo âm tính là 0,932 . Sử dụng điểm cắt $5 \mathrm{ng} / \mathrm{l}$ để chẩn đoán bệnh nhân NMCT thì độ đặc hiệu là 0,957 giá trị dự báo dương tính là 0,887 . Sử dụng điểm cắt $7 \mathrm{ng} / \mathrm{l}$ thì độ đặc hiệu là 0,995 giá trị dự báo dương tính là 0,983.

\section{BÀN LUÂ̂N}

Tỉ lệ HCVC trong nghiên cứu của chúng tôi là 49,7\% (34\% trong tổng số 413 bệnh nhân ban đầu), tỉ lệ này cao hơn trong nghiên cứu của Tobias Reichlin và cộng sự, nghiên cứu 872 bệnh nhân đau ngực tỉ lệ NMCT không ST chênh là $17 \%$, đau thắt ngực không ổn định là $12 \%{ }^{5}$. Ronald Maag và cộng sự nghiên cứu hồi cứu 1772 bệnh nhân thấy rằng khi triệu chứng chính của bệnh nhân là đau ngực thì tỉ lệ NMCT typ 1 trong những bệnh nhân có tăng men tim là $48,5 \%{ }^{6}$ Trong nghiên cứu của chúng tôi tỉ lệ bệnh nhân có tăng troponin T trên $14 \mathrm{ng} / \mathrm{l} \mathrm{khi}$ nhập viện là $53,4 \%$, trong đó bệnh nhân HCVC là $37,5 \%$. Ngưỡng hs troponin T ở mức $14 \mathrm{ng} / \mathrm{l}$ không những gặp ở bệnh nhân NMCT mà còn gặp ở nhiều tình trạng bệnh lý khác do đó khi giải thích kết quả hs troponin $T$ cần kết hợp đánh giá lâm sàng, điện tim cũng như các kết quả cận lâm sàng khác để có chẩn đoán hợp lý.

Nghiên cứu của chúng tôi cho thấy xét nghiệm hs Troponin T 0 -1h cũng như delta hs troponin $\mathrm{T}$ 0-1 giờ có giá trị rất tốt trong chẩn đoán nhồi máu cơ tim ở những bệnh nhân đau ngực với diện tích dưới đường cong AUC lần lượt là 0,$863 ; 0,914 ; 0,932$. Kết quả này cũng tương đương với kết quả từ nghiên cứu của Yonathan Freund nghiên cứu giá trị chẩn đoán NMCT của hs troponin $\mathrm{T}$ so với troponin thế hệ trước với AUC là $0,93 .{ }^{7}$ Phác đồ hs troponin $\mathrm{T}$ 0-1h dùng để chẩn đoán và loại trừ nhanh NMCT cấp không ST chênh lên trong $1 \mathrm{~h}^{8}$. Phác đồ được ESC 2020 khuyến cáo mức độ IA. Phác đồ sử dụng nhiều mức điểm cắt của giá trị troponin T lúc nhập viện và sau $1 \mathrm{~h}$ để đảm bảo khi loại trừ NMCT độ nhạy và giá trị dự báo âm tính tối thiểu là $99 \%$ cũng như thiết lập các ngưỡng tối ưu để đảm bảo những bệnh nhân chẩn đoán NMCT thì giá trị dự báo dương tính trên $70 \%{ }^{8}$. Trong nghiên cứu của chúng tôi khi chọn ngưỡng giá trị hs troponin T lúc nhập viện là $5 \mathrm{ng} / \mathrm{l}$ để loại trừ chẩn đoán NMCT (Rule-out) thì độ nhạy là 0,989 và giá trị dự báo âm tính là 94,9\%. Trong khi đó nếu lấy ngưỡng $52 \mathrm{ng} / \mathrm{l}$ để chẩn đoán NMCT (Rule-in) thì độ đặc hiệu là 0,957 giá trị dự báo dương tính là 0,856 . Với biến đổi nồng độ hs troponin $\mathrm{T} 0-1 \mathrm{~h}$ là $5 \mathrm{ng} / \mathrm{l}$ thì chúng tôi thấy rằng độ đặc hiệu chẩn đoán NMCT là 0,957 giá trị dự báo dương tính là 0,887 trong khi nếu lấy giá trị 7ng/l thì độ đặc hiệu là 0,995. Trong nghiên cứu chúng tôi cũng thấy rằng khi biến đổi nồng độ hs troponin T 0-1h ở những bệnh nhân đau ngực cấp đến cấp cứu trên $5 \mathrm{ng} / \mathrm{l}$ thì đều gặp ở những bệnh nhân có tình trạng tổn thương cơ tim trực tiếp như NMCT, viêm cơ tim hay tắc mạch phổi, những tình trạng bệnh lý này đều là những tình trạng bệnh nặng cần chẩn đoán nhanh để có những điêu trị hợp lý.

\section{KẾT LUÂ̂N}

Bệnh nhân đau ngực cấp vào cấp cứu do nhiều nguyên nhân trong đó HCVC chiếm 49,7\%. Xét nghiệm $\mathrm{Hs}$-Troponin $\mathrm{T}$ và biến thiên HsTroponin T 0-1h có giá trị cao trong chẩn đoán bệnh nhân đau ngực do nhồi máu cơ tim vào cấp cứu. Ở những bệnh nhân đau ngực cấp nồng độ hs troponin T lúc nhập viện càng cao khả năng NMCT càng cao. Biến thiên hs troponin thời điểm $0-1 \mathrm{~h}$ (delta hs troponin $0-1 \mathrm{~h}$ ) càng nhiều thì khả năng NMCT càng cao.

\section{TÀI LIẸU THAM KHẢO}

1. Jerjes-Sánchez $C$. Cardiology in the ER: $A$ Practical Guide. Springer International Publishing; 2019. doi:10.1007/978-3-030-13679-6

2. Thygesen K, Mair J, Giannitsis E, et al. How to use high-sensitivity cardiac troponins in acute cardiac care. Eur Heart J. 2012;33(18):2252-2257. doi:10.1093/eurheartj/ehs154

3. DeLaney MC, Neth M, Thomas JJ. Chest pain triage: Current trends in the emergency departments in the United States. J Nucl Cardiol. 2017; 24(6):2004-2011. doi:10.1007/s12350-016-0578-0

4. Lindner G, Pfortmueller CA, Braun CT, Exadaktylos AK. Non-acute myocardial infarctionrelated causes of elevated high-sensitive troponin $T$ in the emergency room: a cross-sectional analysis. Intern Emerg Med. 2014;9(3):335-339. doi:10.1007/s11739-013-1030-y

5. Reichlin T, Schindler C, Drexler B, et al. OneHour Rule-out and Rule-in of Acute Myocardial Infarction Using High-Sensitivity Cardiac Troponin T. Arch Intern Med. 2012;172(16):1211. doi:10.1001/archinternmed.2012.3698

6. Maag $R$, Sun $S$, Hannon $M$, Davies $R$, Alagona P, Foy A. Positive predictive value of an elevated cardiac troponin for type I myocardial infarction in ED patients based on the chief complaint. The American Journal of Emergency Medicine. 2015; 33(4):516-520. doi:10.1016/j.ajem.2015.01.003

7. Freund $Y$, Chenevier-Gobeaux $C$, Bonnet $P$, 
et al. High-sensitivity versus conventional troponin in the emergency department for the diagnosis of acute myocardial infarction. Crit Care. 2011;15(3):R147. doi:10.1186/cc10270

8. Collet J-P, Thiele H, Barbato E, et al. 2020 ESC
Guidelines for the management of acute coronary syndromes in patients presenting without persistent ST-segment elevation. European Heart Journal. 2021;42(14):1289-1367. doi:10.1093/ eurheartj/ehaa575

\title{
PHÂN TÍCH GEN SLC25A20 VÀ CPT2 TRONG CHẨN ĐOÁN KHIẾM KHUYẾT BETA OXI HOÁ CỦA AXÍT BÉO Ở TI THỂ
}

\author{
Phạm Thúy Ngọc ${ }^{1}$, Bùi Thị Bảo², Tạ Văn Thạo³, \\ Vũ Chí Dũng ${ }^{4}$, Trần Thị Chi Mai ${ }^{3,4}$
}

\section{TÓM TĂT}

Bệnh lí thiếu hụt Carnitine/acylcarnitine transferase (CACT) và bệnh lí thiếu hụt Carnitine palmitoyltransferase II (CPT II) thuộc nhóm bệnh oxi hóa axit béo trong ti thê. CACT và CPT II là các bệnh lí rối loạn chuyển hóa bẩm sinh (RLCHBS) di truyền hiếm gặp - biến thể di truyền lặn nhiễm sắc thể thường do gen SLC25A20 (gen CACT) và gen CPT2 quy định. Đây là các bệnh lí nguy hiểm để lại các di chứng nặng nề và có thể tử vong. Tuy nhiên, CACT và CPT II có các đặc điểm lâm sàng và cận lâm sàng khá giống với các bệnh lí RLCH oxi hóa axit béo khác và không thể phân biệt về đặc điểm cận lâm sàng và lâm sàng giữa hai bệnh lí này do vầy cân có các phương pháp phù hợp, nhanh chóng để xác định biến thể trên gen SLC25A20 và CPT2 nhằm chẩn đoán và điều trị bệnh. Mục tiêu: Xác định 16 biến thể gen SLC25A20 và 35 biến thể gen CPT2; mô tả kiểu hình và kiểu gen của bệnh nhân mắc biến thể gen SLC25A20/CPT2. Phương pháp: Nghiên cứu ca bệnh gồm mô tả triệu chứng lâm sàng, xét nghiệm sinh hóa và phân tích gen dựa trên phương pháp xây dựng được. Kết quả: Bé gái 10 ngày tuổi, xuất hiện tím tái, ngừng tim, ngưng thở và tử vong. Kết quả xét nghiệm sinh hóa và xét nghiệm amio acid cho thấy hạ glucose máu, nhiễm toan chuyển hóa, tăng amoniac máu; tăng C4, C10, C12, C14, C14OH, C16, C16:1, $\mathrm{C} 16: 10 H$, $\mathrm{C} 18$ và $\mathrm{C} 18: 1$. Bệnh nhân được xác định có biến thể rs541208710, c.199-10T>G dạng đồng hợp tử trên gen SLC25A20 và 2 biến thể lành tính/ có thể lành tính với bệnh CPT II là rs2229291 (F352C) (c.1055T>G (p.Phe352Cys)) và rs1799821 (V368I) (c.1102G >A (p.Val368Ile)) do vây chẩn đoán bênh di truyền mắc phải là bệnh CACT. Kết luận: Xác định 16 biến thể gen SLC25A20 và 35 biến thể gen CPT2 cho phép chẩn đoán xác định bệnh lí RLCHBS di truyền CACT và CPT II.

\footnotetext{
${ }^{1}$ Bệnh viện Phổi Trung Uơng

${ }^{2}$ Công ty cổ phần Chemedic Việt Nam

${ }^{3}$ Đại họ Y Hà Nọi

${ }^{4}$ Bệnh viện Nhi Trung Uơng

Chiu trách nhiệm chính: Ta Văn Thạo

Email: tavanthao@hmu.edu.vn

Ngày nhận bài: 9.9.2021

Ngày phản biên khoa họ: 29.10.2021

Ngày duyệt bài: 9.11.2021
}

Tư khóa: Rối loạn chuyển hóa bẩm sinh (RLCHBS), thiếu hụt Carnitine/acylcarnitine (CACT), thiếu hụt Carnitine palmitoyltransferase II (CPT II), gen SLC25A20, gen CPT2.

\section{SUMMARY}

ANALYSIS OF SLC25A20 AND CPT2 GENES IN THE DIAGNOSIS OF MITOCHONDRIAL FATTY ACID BETA-OXIDATION DEFECT

Carnitine-acylcarnitine translocase deficiency (CACT) and Carnitine palmitoyltransferase II deficiency (CPT II) are disorders of mitochondrial fatty acid $\beta$-oxidation (FAO), type of metabolism inborn errors. These conditions are inherited in an autosomal recessive pattern, the gene associated with this disorder respectively SLC25A20 (CACT gene) and CPT2 gene. CACT and CPT II are dangerously disordered and may have severe consequences and even death. But these disorders had similar and nonspecific clinical symptoms also testing with another FAO disorder and other metabolism inborn errors or congenital defect, specifically, cannot distinguish and diagnostic between CACT and CPT II disorder. Therefore, this is necessary for a suitable method and quicky time for diagnostic mutation in SLC25A20 and CPT II gene to diagnostic and treat diseases. Objectives: to identify 16 mutations in the SLC25A20 gene and 35 mutations in the CPT2 gene to describe the phenotype and genotype of the patient who had SLC25A20/CPT2 mutation. Methods: case study including clinical symptom descriptions and identifying SLC25A20/CPT2 mutation. Results: the newborn girl-patient 10 days old with clinical symptoms include cyanosis, cardiac arrest, apnea, and death. The blood testing reveals that decrease glucose, metabolism acidosis, hyperammonemia, increase C4, C10, C12, C14, C14OH, C16, C16:1, $\mathrm{C} 16: 1 \mathrm{OH}, \mathrm{C} 18$ and $\mathrm{C} 18: 1$. The genetic test showed that the patient had one pathology homozygous mutation rs541208710, c.199-10T>G in SLC25A20 gene and two other mutation - benign/likely benign with CPT II deficiency in CPT2 gene are rs2229291 (F352C) (c.1055T > G (p.Phe352Cys)) and rs1799821 (V368I) (c.1102G $>$ A (p.Val368Ile)). The diagnosis is CACT deficiency. Conclusion: Identifying 16 mutations in the SLC25A20 gene and 35 mutations in the CPT2 genes can help to diagnostic CACT/CPT II deficiency. 